\title{
Macrocyclic Oligomeric Arylene Ether Ketones: Synthesis and Polymerization
}

\author{
Hongyan JIANG, ${ }^{\dagger}$ Tianlu CHEN, $^{\dagger}$ Yinghua QI, and Jiping XU \\ Changchun Institute of Applied Chemistry, Chinese Academy of Sciences, \\ Changchun, 130022, People's Republic of China
}

(Received August 25, 1997)

\begin{abstract}
Some novel macrocylic(arylene ether ketone)oligomers were synthesized in high yields by a nucleophilic aromatic substitution reaction of 4,4'-dinitrobenzophenone with bisphenols in the presence of anhydrous potassium carbonate under pseudo-high-dilution conditions. Detailed structural characterization of these oligomers by matrix-assisted laser desorption/ionization-time of flight-mass spectrometry (MALDI-TOF-MS), ${ }^{1} \mathrm{H}$ NMR and FT-IR confirmed their cyclic nature and the compositions of the oligomeric mixtures was indicated by GPC analysis. Ring-opening polymerization of cyclic oligomers 3a to a high molecular weight polymer with $M_{w}$ of 52.3 and $M_{n}$ of $17.2 \mathrm{k}$ was achieved by heating at $280^{\circ} \mathrm{C}$ for $40 \mathrm{~min}$ in the presence of a nucleophilic initiator.

KEY WORDS Macrocyclic(arylene ether ketone)oligomers / Ring-Opening Polymerization /
\end{abstract}

Poly(arylene ether)s are rapidly increasing in technological importance due to their toughness, lightness, dimensional stability at high temperatures and good insulating properties. However, these high-performance polymers are very difficult to process due to high softening temperatures and especially the high melt viscosities which limit wider application in fibre impregnation and microscale fabrication. The advantages of using cyclic(arylene ether ketone)s ${ }^{1-15}$ and cyclic(arylene ether sulfone) $\mathbf{s}^{16-20}$ as precursors of high-performance thermoplastics were recognized. Cyclic oligomers offer low melt viscosity and the possibility of controlled polymerization in a melt without liberation of volatile byproducts. These features are particularly valuable for the manufacture of advanced composite materials. However, most cyclic(arylene ether)s reported are prepared starting with difluoro-monomers. This paper reports the synthesis, characterization, and ring-opening polymerization of novel cyclic(arylene ether ketone)oligomers prepared from nucleophilic aromatic substitution reactions of $4,4^{\prime}$-dinitrobenzophenone with bisphenols, which still proceeds in high yields.

\section{EXPERIMENTAL}

\section{Materials}

Reagent-grade solvents dimethylformamide (DMF) and toluene were used without further purification, $4,4^{\prime}$-dinitrobenzophenone was prepared at this lab. ${ }^{21}$ The others were commercially available.

\section{General Instruments}

Gel permeation chromatography (GPC) was performed on a Shimadzu LC-4A apparatus equipped with two columns of DuPont ZORBAX-PSM-60S and 1000S, and a UV detector ( $254 \mathrm{~nm}$ ) using tetrahydrofuran (THF) as the eluent at a flow rate of $0.5 \mathrm{~mL} \mathrm{~min}^{-1}$. The columns were calibrated with a mixture of six polystyrene standards. Matrix-assisted laser desorption/ionization-time of flight (MALDI-TOF) mass spectra were recorded on

† To whom correspondence should be addressed. a LDI-1700 instrument at a wavelength of $337 \mathrm{~nm}\left(\mathrm{~N}_{2}\right.$ laser light) using 2,5-dihydroxybenzoic acid as the matrix. The MALDI was operated in a positive linear mode. Nuclear magnetic resonance (NMR) proton spectra were recorded on a Varian Unity-400 NMR spectrometer at $400 \mathrm{MHz}$ in $\mathrm{CDCl}_{3}$ using tetramethylsilane (TMS) as the standard. Infrared spectra $(\mathrm{KBr}$ pellets) were recorded on a BIO-RAD FTS-7 spectrometer. Thermal analysis was carried out on a PerkinElmer 7 Series Thermal Analysis System. The heating rate was $10^{\circ} \mathrm{C} \mathrm{min}^{-1}$ in a nitrogen atmosphere.

\section{General Procedure for Synthesis of Cyclic Oligomers}

The cyclization reaction of phenolphthalein and $4,4^{\prime}$-dinitrobenzophenone was conducted in a $500 \mathrm{~mL}$ four-neck round-bottom flask equipped with a nitrogen inlet, thermometer, and condenser. The flask was charged with $300 \mathrm{~mL}$ of DMF, $30 \mathrm{~mL}$ of toluene and $2.0 \mathrm{~g}$ anhydrous potassium carbonate. The solution was mechanically stirred and heated to $145^{\circ} \mathrm{C}$. A solution of phenolphthalein $(2.55 \mathrm{~g}, 8 \mathrm{mmol})$ and 4,4'-dinitrobenzophenone $(2.18 \mathrm{~g}, 8 \mathrm{mmol})$ in $40 \mathrm{~mL}$ of DMF was added over a period of $10 \mathrm{~h}$. The resulting solution was refluxed until the violet-red solution turned pale yellow. The reaction solution was cooled and filtered to remove all salt. The solvent was then removed from the filtrate at reduced pressure. The residue was boiled in distilled water for a period of $30 \mathrm{~min}$. The desired cyclic oligomers were obtained as a pale yellow powder and dried in a vacuum oven $\left(100^{\circ} \mathrm{C}\right)$ for $12 \mathrm{~h}$. The yield of $3 \mathrm{a}$ was $2.94 \mathrm{~g}$ (74\% yield). FT-IR (KBr): 1770.7 (ester $\mathrm{C}=\mathrm{O}), 1654.6$ $(\mathrm{C}=\mathrm{O}) \mathrm{cm}^{-1} .{ }^{1} \mathrm{H}$ NMR $\left(\mathrm{CDCl}_{3}\right): \delta 7.98(\mathrm{~m}, 1 \mathrm{H}), 7.79$ $(\mathrm{m}, 5 \mathrm{H}), 7.60(\mathrm{~m}, 2 \mathrm{H}), 7.37(\mathrm{~m}, 4 \mathrm{H}), 7.05(\mathrm{~m}, 8 \mathrm{H}) . \mathrm{A}$ similar procedure was applied for the preparation of 3b-3c. The yield of $\mathbf{3 b}$ was $2.56 \mathrm{~g}(61 \%$ yield). FT-IR (KBr): $2919.8\left(-\mathrm{CH}_{3}\right), 1769.8($ ester $\mathrm{C}=\mathrm{O}), 1675.5(\mathrm{C}=\mathrm{O})$ $\mathrm{cm}^{-1} .{ }^{1} \mathrm{H} \mathrm{NMR}\left(\mathrm{CDCl}_{3}\right): \delta 7.98(\mathrm{~m}, 1 \mathrm{H}), 7.82-7.87(\mathrm{~m}$, $5 \mathrm{H}), 7.75(\mathrm{~m}, 2 \mathrm{H}), 7.60(\mathrm{~m}, 2 \mathrm{H}), 7.15(\mathrm{~m}, 2 \mathrm{H}), 6.87-6.94$ $(\mathrm{m}, 6 \mathrm{H}), 2.13\left(\mathrm{~s}, 6 \mathrm{H},-\mathrm{CH}_{3}\right)$. The yield of $3 \mathrm{c}$ was $2.27 \mathrm{~g}$ $(70 \%)$. FT-IR (KBr): $1655.6(\mathrm{C}=\mathrm{O}) \mathrm{cm}^{-1} .{ }^{1} \mathrm{H}$ NMR $\left(\mathrm{CDCl}_{3}\right): \delta 7.71(\mathrm{~d}, 4 \mathrm{H}, J=8.8 \mathrm{~Hz}), 6.99(\mathrm{~d}, 4 \mathrm{H}, J=8.8$ $\mathrm{Hz}), 7.24$ (d, 4H, $J=8.8 \mathrm{~Hz}), 6.97$ (d, $4 \mathrm{H}, J=8.8 \mathrm{~Hz})$. 


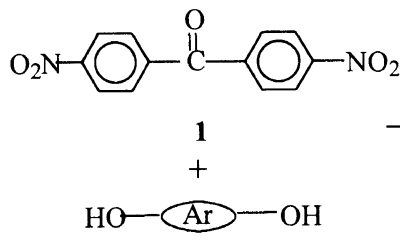

2a-c

a.

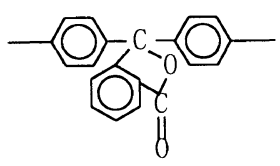

b.<smiles>Cc1cccc(C2(c3ccc(C)c(C)c3)OC(=O)c3ccc(C)cc32)c1</smiles>

Scheme 1.
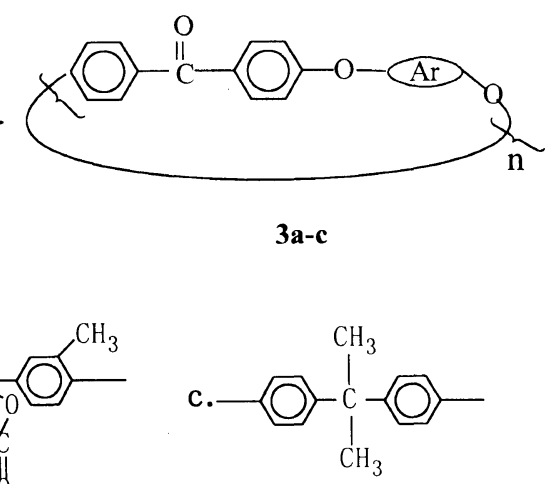

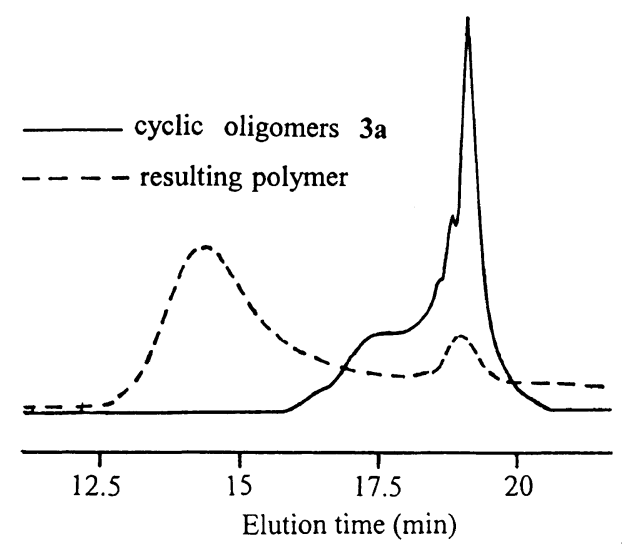

Figure 1. GPC traces of cyclic oligomers 3a and resulting polymers.

\section{Ring-Opening Polymerization of 3a}

In a $50 \mathrm{~mL}$ flask, cyclic oligomers 3a $(0.50 \mathrm{~g})$ were mixed with potassium $4,4^{\prime}$-biphenoxide $(0.01 \mathrm{~g})$. The flask was heated in nitrogen atmosphere at $280^{\circ} \mathrm{C}$ for $40 \mathrm{~min}$ to give the corresponding polymer which was partially insoluble in chloroform and THF. The reduced viscosity of the soluble fraction in chloroform is $0.26 \mathrm{dL} \mathrm{g}^{-1}$, approximately one third that of the commercial PEK-C sample $\left(0.79 \mathrm{dL} \mathrm{g}^{-1}\right)$. GPC analysis shows that the high molecular weight fraction has an $M_{w}$ of 52.3 and an $M_{n}$ of $17.2 \mathrm{k}$.

\section{RESULTS AND DISCUSSION}

Cyclic oligomers $\mathbf{3 a}-\mathbf{3} \mathbf{c}$ were prepared in high yields by a nucleophilic aromatic substitution reaction from the potassium salt, prepared in situ, of the bisphenols $\mathbf{2 a - 2 c}$ with 4,4'-dinitrobenzophenone under pseudo-high-dilution conditions (Scheme 1). A concentrated solution $(0.2 \mathrm{M})$ of the reactants 1 and $2 \mathbf{a}$ or $\mathbf{2 b}$ or $\mathbf{2 c}$ in $N, N$ DMF was added dropwise to a mechanically stirred vessel containing solvent (DMF) and base $\left(\mathrm{K}_{2} \mathrm{CO}_{3}\right)$ over a period of $10 \mathrm{~h}$. Refluxing temperature was controlled at $145^{\circ} \mathrm{C}$ by varying the amount of the azeotropic solvent toluene. The solution was refluxed for another $10 \mathrm{~h}$ to ensure complete reaction. The cyclization reaction led to low molecular weight oligomers. The oligomeric materials were soluble in solvents such as DMF, dimethyl sulfoxide (DMSO), THF, and chloroform. GPC analysis of the product $3 \mathbf{a}-\mathbf{3 c}$ revealed a series of resolved peaks in the low molecular weight

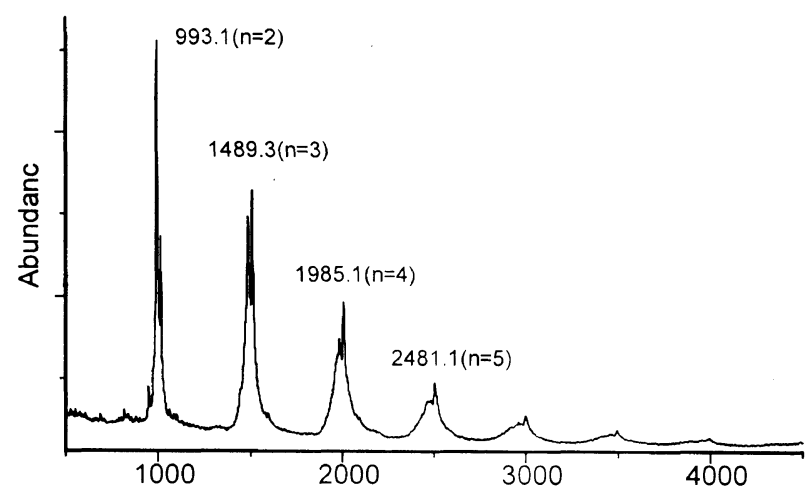

Figure 2. MALDI-TOF-MS spectrum of cyclics $\mathbf{3 a}$.

region with $M_{n}$ of $1.5,1.6$, and $1.1 \mathrm{k}$, respectively, and $M_{w}$ of $4.2,5.3$, and $1.6 \mathrm{k}$, respectively (against polystyrene standard). A typical GPC trace of 3a was shown in Figure 1. Confirmation of the cyclic nature of these oligomers was made using matrix-assisted laser desorption/ionization-time of flight-mass spectrometry (MALDI-TOF-MS). MALDI-TOF-MS indicated that the cyclic oligomers $3 \mathbf{a}-\mathbf{3 c}$ consist principally of macrocycles with repeating units of $2-7$. MALDI-TOFMS spectrum of 3a, using 2,5-dihydroxybenzoic acid as the matrix, gives the correct molecular ion peaks for $\left[M_{n}\right]^{+}$and sodium adducts $\left[M_{n}+\mathrm{Na}\right]^{+}$of the desired macrocyclic oligomers with reasonable signal to noise ratio (Figure 2). The signals for cyclic trimer of 3a are located at 1489.3 and 1511.3 Da. The signal at 1489.3 Da corresponds to the protonated molecular ion peak, and that at $1511.3 \mathrm{Da}$ is due to the adduct of the trimer with a sodium cation. In addition to the molecular ion peaks for $\left[M_{n}+\mathrm{H}\right]^{+}$and $\left[M_{n}+\mathrm{Na}\right]^{+}$, the MALDI-TOF-MS spectra of $\mathbf{3 b}$ and $\mathbf{3 c}$ (Figure 3 ) also given molecular ion peaks for potassium adducts $\left[M_{n}+\mathrm{K}\right]^{+}$which may result from the residual potassium carbonate in the final products. Traces of linear oligomers were observed. Based upon peak area measurements in the mass spectra, we estimate that the cyclic dimer of $\mathbf{3 b}$ is accompanied by about $8 \%$ linear oligomers and the dimer of $3 \mathbf{c}$ is accompanied by about $5 \%$ linear oligomers.

Based on integration of the peak area, GPC analysis showed that macrocyclic oligomers $3 \mathrm{a}$ contain $41.9 \%$ cyclic dimer, $13.8 \%$ cyclic trimer, $6.6 \%$ cyclic tetramer and $44.3 \%$ higher homologues. Cyclics 3 b contain $47.0 \%$ cyclic dimer, $10.6 \%$ trimers, $8.2 \%$ tetramer, and $34.2 \%$ higher homologues $(n>4)$. Macrocyclic oligomers 3a 
contain $46.5 \%$ cyclic dimer, $10.8 \%$ cyclic trimer and $42.7 \%$ higher homologues $(n>3)$. The cyclic dimer is the predominant product in any case. The macrocyclic dimer of $3 c$ can be recrystallized from a methylene chloride solution of cyclic oligomers $3 \mathbf{c}$. The size of the macrocycle was confirmed by the molecular ion peak at $m / z=$ 814.5 Da in the MALDI-TOF-MS spectrum. The X-ray structure of the cyclic dimer of $3 \mathbf{c}$ has been resolved ${ }^{14}$ Analysis of the X-ray structure showed the cyclic dimer of $3 \mathbf{c}$ a less-strained macrocycle. Since pseudo-highdilution may favor the formation of smaller ring size cyclic oligomers as a result of dilution beyond a critical concentration as suggested by Jacobson and Stockmayer (J-S theory), ${ }^{22}$ these less-strained macrocyclic dimers are preferably formed.

Thermal analysis of macrocyclic oligomers 3a shows a small $T_{\mathrm{g}}$ peak at $133.4^{\circ} \mathrm{C}\left(\Delta C_{\mathrm{p}}=0.242 \mathrm{~J} \mathrm{~g}^{-1} \cdot{ }^{\circ} \mathrm{C}\right)$ and another $T_{\mathrm{g}}$ peak at $246.8^{\circ} \mathrm{C}\left(\Delta C_{\mathrm{p}}=0.553 \mathrm{~J} \mathrm{~g}^{-1} \cdot{ }^{\circ} \mathrm{C}\right)$. No melt endotherm peak was observed up to $450^{\circ} \mathrm{C}$, indicating amorphous morphology. Macrocyclic oligomers 3a begin to melt at $268^{\circ} \mathrm{C}$ and form a homogeneous melt near $290^{\circ} \mathrm{C}$. Macrocyclic oligomers 3b show a small $T_{\mathrm{g}}$ peak at $145^{\circ} \mathrm{C}$ and another $T_{\mathrm{g}}$ peak at $229.5^{\circ} \mathrm{C}$
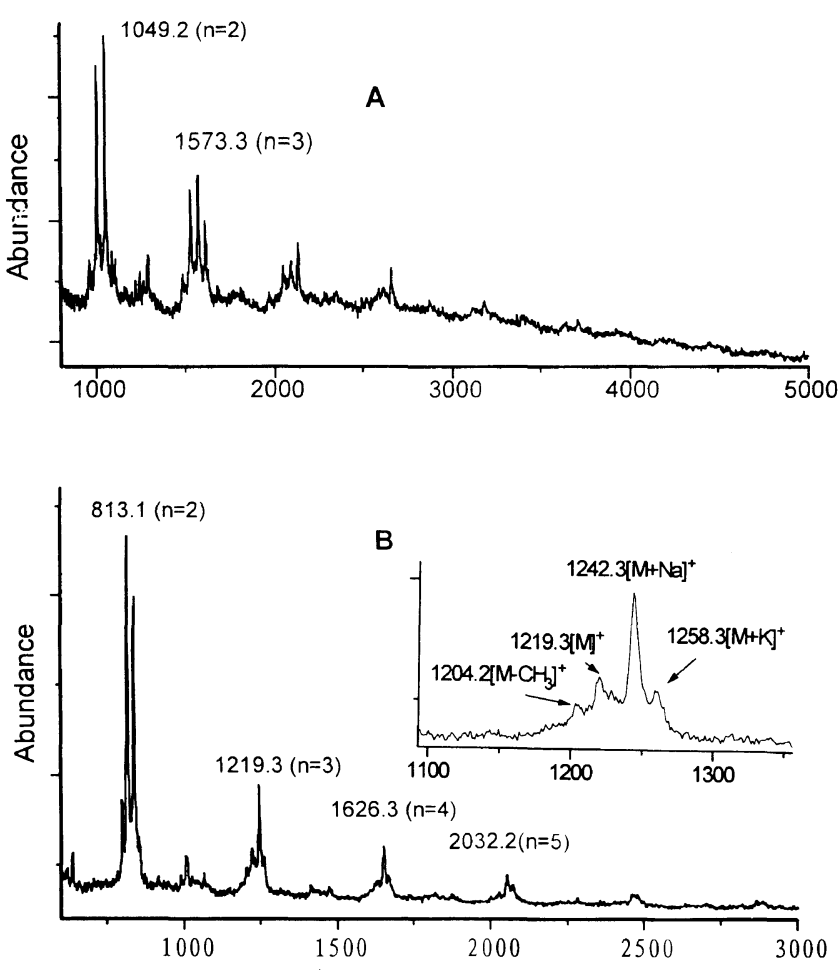

Figure 3. MALDI-TOF mass spectra of cyclic oligomers $\mathbf{3 b}(\mathrm{A})$ and $3 c(B)$.
$\left(\Delta C_{\mathrm{p}}=0.299 \mathrm{~J} \mathrm{~g}^{-1 .}{ }^{\circ} \mathrm{C}\right)$. No melt endotherm peak was observed up to $450^{\circ} \mathrm{C}$. However, the DSC scan of the cyclic oligomers 3c showed an exotherm at $167.39^{\circ} \mathrm{C}$ $\left(\Delta H_{\mathrm{c}}, 12.44 \mathrm{~J}^{-1}\right)$ and a broad endotherm at $386.85^{\circ} \mathrm{C}$ (midpoint, $\Delta H_{\mathrm{m}}, 61.71 \mathrm{~J} \mathrm{~g}^{-1}$ ), indicating a semicrystalline material.

Since ether linkages are activated by para-carbonyl groups, they are potentially susceptible to nucleophilic cleavage $^{23}$ (Scheme 2). The polymerization of macrocyclic oligomers 3a was carried out in nitrogen atmosphere at $280^{\circ} \mathrm{C}$ in the presence of $2.0 \%(\mathrm{w} / \mathrm{w})$ potassium 4,4'-biphenoxide for $40 \mathrm{~min}$. Polymerization of macrocyclic oligomers 3a resulted in a tough material which, unlike the commercial phenolphthalein polyetherketone (PEK-C), ${ }^{24}$ was partially insoluble in chloroform and THF. About $80 \%$ (weight) of the resulting polymer is soluble in THF. A GPC trace of the soluble fraction is showed in Figure 1, which clearly shows the formation of high molecular weight linear polymer. The high molecular weight fraction has an $M_{w}$ of 52.3 and $M_{n}$ of $17.2 \mathrm{k}$ with a molecular weight distribution of 3.0. GPC analysis also shows that about $10.5 \%$ cyclic oligomers remained in the final polymer. Prolonging the polymerization time to $1 \mathrm{~h}$ gave less cyclic oligomers $(6.5 \%)$ and the soluble fraction of the high molecular weight materials was considerably reduced to $65 \%$. The insolubility of PEK-C prepared from cyclics probably resulted from side reactions at the high reaction temperatures. About $85 \%$ (weight) of the PEK-C prepared from ring-opening polymerization was soluble in chloroform and the soluble fraction had a reduced viscosity of $0.26 \mathrm{dL} \mathrm{g}^{-1}(0.5 \%$ in chloroform at $25^{\circ} \mathrm{C}$ ) which was approximately one third that of the commercial PEK-C sample $\left(0.79 \mathrm{dL} \mathrm{g}^{-1}\right)$. The lower viscosity of the PEK-C prepared from cyclis may originate from the presence of linear oligomers in the cyclic oligomers which act as chain-transfer agents in the ring-opening polymerization reaction. The lower viscosity can also be attributed to the remaining of some cyclic oligomers in the final polymer. Thermal analysis of the resulting PEK-C polymer shows a glass transition temperature of $216.1^{\circ} \mathrm{C}$ which is a little lower than that for the commercial PEK-C $\left(T_{\mathrm{g}}=228^{\circ} \mathrm{C}\right)$ and shows a $5 \%$ weight loss at $407.5^{\circ} \mathrm{C}$ in a nitrogen atmosphere.

Melt polymerization of cyclics $3 \mathbf{c}$ was performed at $390^{\circ} \mathrm{C}$ in the presence of $2.0 \%(\mathrm{w} / \mathrm{w})$ potassium $4,4^{\prime}-$ biphenoxide for $40 \mathrm{~min}$ and resulted in an amber-colored product. Unlike the cyclic oligomers, the product was insoluble in many common solvents, so GPC analysis was impossible, DSC analysis showed a $T_{\mathrm{g}}$ of $159.8^{\circ} \mathrm{C}$.

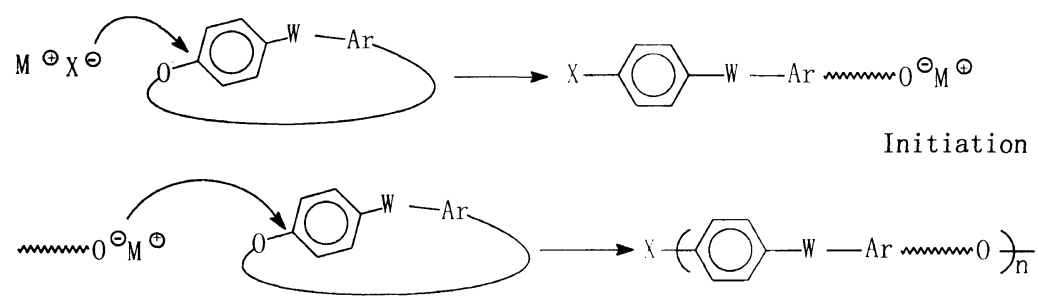

$\mathrm{M}=\mathrm{K} \quad \mathrm{X}=\mathrm{OAr} \mathrm{W}=$ Electron withdrawing group, $\mathrm{CO}$

Propagation

Scheme 2. Polymerization of cyclic(arylene ether ketone)s via transetherification reaction in the presence of a nucleophilic initiator. 


\section{CONCLUSIONS}

We demonstrated use of ring-opening polymerization of cyclic oligomers to produce linear poly(arylene ether ketone) polymers. These preliminary experiments produced good yields of cyclic oligomers. Ring-opening polymerization produced the corresponding polymers. The polymers prepared from ring-opening polymerization had poor solubility in many common solvents. We believe that changes in catalyst structures and removal of linear oligomers from the cyclics will produce soluble polymers. Further work will be directed toward the optimization of the cyclization reaction and detailed polymerization study.

Acknowledgments. We thank the Polymer Chemistry Laboratory, Changchun Institute of Applied Chemistry and Chinese Academy of Sciences (CAS) and Chinese Petrol-Chemical Corporation for financial support.

\section{REFERENCES}

1. J. A. Cella, J. J. Talley, and J. M. Fukuyama, Polym. Prepr. (Am. Chem. Soc., Div. Polym. Chem.), 30, 581 (1989).

2. H. M. Colquhoun, C. C. Dudman, M. Thomas, C. A. O'Mahoney, and D. J. Williams, J. Chem. Soc., Chem. Commun., 336, (1990).

3. J. M. Fukuyama, U.S. Patent 4959454 (1990).

4. J. M. Fukuyama, U.S. Patent 5110893 (1992).

5. M. J. Mullins, E. P. Woo, K. E. Balon, D. J. Murray, and C. C. Chen, U.S. Patent 5264538 (1993).
6. K. P. Chan, Y. Wang, and A. S. Hay, Macromolecules, 28, 653 (1995).

7. K. P. Chan, Y. Wang, and A. S. Hay, Polym. Prepr. (Am. Chem. Soc., Div. Polym. Chem.), 36, 653 (1995).

8. Y. Wang, K. P. Chan, and A. S. Hay, Polym. Prepr. (Am. Chem. Soc., Div. Polym. Chem.), 36, 130 (1995).

9. C. P. Gao and A. S. Hay, Polymer, 36, 4141 (1995).

10. K. P. Chan, Y. Wang, A. S. Hay, X. L. Hronowski, and R. J. Cotter, Macromolecules, 28, 6705 (1996).

11. Y. Ding and A. S. Hay, Macromolecules, 29, 3090 (1996).

12. Y-F. Wang, M. Paventi, K. Chan, and A. S. Hay, J. Polym. Sci., Part A, Polym. Chem., Ed., 34, 2135 (1996).

13. M. F. Chen and H. W. Gibson, Macromolecules, 29, 5502 (1996).

14. H. Y. Jiang, Y. H. Qi, T. L. Chen, Y. Xing, and J. P. Xu, J. Polym. Sci., Part A, Polym. Chem., Ed., 35, 1753 (1997).

15. Y. Wang, M. Paventi, and A. S. Hay, Polymer, 38, 469 (1997).

16. M. J. Mullins, R. Galvan, M. T. Bishop, E. P. Woo, D. B. Gorman, and T. A. Chamberlin, Polym. Prepr. (Am. Chem. Soc., Div. Poly. Chem.), 32, 174 (1991).

17. M. J. Mullins, R. Galvan, M. T. Bishop, E. P. Woo, D. B. Gorman, and T. A., Chamberlin, Polym. Prepr. (Am. Chem. Soc., Div. Polym. Chem.), 33, 414 (1992).

18. M. J. Mullins, E. P. Woo, D. J. Murry, and T. M. Bishop, CHEMTECH, 25 (August, 1993).

19. D. Xie and H. W. Gibson, Polym. Prepr. (Am. Chem. Soc., Div. Polym. Chem.), 35, 401 (1994).

20. H. Y. Jiang, T. L. Chen, S. Q. Bo, and J. P. Xu, Macromolecules, 30, 7345 (1997).

21. Z. G. Wang, Ph.D. dissertation, CIAC, CAS, Changchun, People's Republic of China, 1994.

22. H. Jacobson and W. H. Stockmayer, J. Chem. Phys., 18, 1600 (1950).

23. A. Bunn, Br. Polym. J., 20, 307 (1988).

24. H. C. Zhang, T. L. Chen, and Y. G. Yuan, Chinese Patent 85108751.5 (1985). 